\title{
A Qualitative Study on the Influencing Factors of Public Participation in the Construction of "Waste-Free City" Exploratory Analysis Based on Grounded Theory
}

\author{
Mao Chai ${ }^{1}$, Jing Jiao ${ }^{1 *}$, Yu Han ${ }^{2}$ \\ ${ }^{1}$ School of Public Administration, Xiangtan University Xiangtan, Hunan P.R. China \\ ${ }^{2}$ School of Public Administration, Northwest University Xi 'an, Shaanxi P.R. China
}

\begin{abstract}
As a cellular project of beautiful China and a systematic project of the whole people, the construction of "Waste Free City" cannot be separated from the extensive participation of the public. This research in China's Henan province "no waste city" construction of public participation as the research object, using the grounded theory, first through open and spindle coding that affecting public participation "no waste city" of the construction of the six main factors: attitude, subjective norm, perceived behavioral control, driving factors and social environment and identity characteristics; Then a model of influencing factors of public participation is constructed through selective coding. The results show that participation attitude, subjective norms and perceived behavior control directly affect the willingness of the public to participate in the construction of "waste-free city", which are internal psychological factors. Government behavior, group influence, community factor and enterprise factor constitute the external environmental factors that affect public participation. The three categories of publicity and education, reward and punishment mechanism and laws and regulations form the driving factors of public participation in the construction of "waste-free city", which play a moderating role between internal psychological factors and external environmental factors. At the same time, identity characteristics also directly affect the public participation behavior in the construction of "waste-free city".
\end{abstract}

\section{Problem Raising and Literature Review}

With the continuous development of economy and society, and the accelerating process of urbanization and industrialization, China's annual increase of solid waste amounts to about 10 billion tons, and the trend of growth year by year, seriously affecting the sustainable development of urban economy. In order to reduce the negative impact of solid waste on the ecological environment, "Waste Free City" is a new urban development model guided by the five new development concepts and using green production development as the means. The Fifth Plenary Session of the 19th CPC Central Committee made major strategic arrangements for the construction of ecological civilization and ecological environmental protection. It puts forward the long-term goal of "basically realizing the goal of building a beautiful China" in 2035 and the new goal and task of "realizing new progress in ecological civilization construction" in the "14th Five-Year" period. On May 6, 2021, [1] the National Development and Reform Commission issued the "14th Five-Year Plan for the Development of Urban Domestic Waste Classification and Disposal Facilities", which provides another important institutional guarantee for the development of "Waste Free Cities". As a systematic project of the whole people, the steady progress of the construction of "waste-free city" cannot be separated from the extensive participation of the whole public.

Foreign research and exploration on the construction of "waste-free city" started earlier, and the concept of "waste-free" or "zero waste" began to appear in the 1990s. At the national level, At the national level, Japan, the United Kingdom, Singapore [2] have implemented the "zero waste" strategy earlier. At the urban level, New York and San Francisco in the US, Vancouver in Canada, and Stockholm in Sweden have all announced their zero-waste plans. In C40 City Group, an international organization of cities to jointly deal with climate change, 23 cities have also signed the Declaration toward Zero Waste [3]. Compared with foreign studies, the exploration of "wastefree city" in China started relatively late. China's "Zero Abandoned" Alliance was established in December 2011, and academic discussions on "waste-free city" were almost zero before 2018, but there has been a significant increase in recent years. Research topics can be roughly divided into solid waste management and resource utilization, the construction pattern and development path to explore, scheme evaluation and effectiveness evaluation three categories, there are also involved in construction waste recycling use of the recycled product [4], risk of hazardous wastes and their legal regulation [5], 
as well as China's provincial cities without waste "spacetime evolution trend of the development level of study [6], etc.

In addition, many domestic scholars have conducted related studies on public participation in ecological civilization construction from different perspectives, covering natural environment governance, public environmental protection behavior, ecological function area construction, ecological city construction, etc. Among them, some research conclusions have important reference significance for this study. First, The first is the research on the influencing factors of public participation in the construction of ecological civilization. The academic discussion on this topic mainly includes subject factor [7], objective factor [8], external environment [9] and so on. Second, the study on the path and mechanism of public participation in ecological civilization construction. Specifically, it includes the cultivation path of ecological environmental awareness [10], the judicial path of public participation in environmental protection [11], the "empowerment, identification and cooperation" mechanism of public participation in environmental governance [12], and the community action and collective cooperation in environmental protection [13].

To sum up, the research results on public participation in ecological civilization construction have been quite fruitful, which has important enlightenment for the study of the influencing factors of public participation in the construction of "waste-free city". "No waste city" as a new urban development pattern, public participation "no waste city" construction is different from general environmental volunteering, uniqueness, and few of the current "no waste city" related research on public participation in the discussion, so it is necessary for the public to participate in the "no waste city" of the construction of the influencing factors and explore the mechanism of action, To provide theory and experience for the better development of "waste free city".

\section{Study Design}

\subsection{The research methods}

Grounded theory is a qualitative research method based on systematically collecting and processing data, and then extracting concepts and constructing models from the bottom up. [14] It develops a theoretical model through coding and refining data, which is very suitable for exploring the influencing factors of public participation. In addition, the theory of planned behavior has been widely used to explain and predict the decision-making process of individual behavior due to its outstanding explanatory and predictive ability. [15] Therefore, this study combined with the theory of planned behavior, processed and analyzed the data through the three-level coding of the grounded theory, constructed a theoretical model, and revealed the main factors affecting the public participation in the construction of "waste-free city".

\subsection{Sample selection}

This study selected of public participation in China's henan province "no waste city" as the research object on the construction of major for two reasons: one is as zhongyuan urban agglomeration in China only pilot "no waste city" construction, the authors formed the advanced experience of the solid waste disposal and characteristic pattern, won several authoritative media coverage in China. Second, Xuchang gave full play to the role of system guarantee, market drive, technical support and cultural maintenance to guide the active participation of the public, and its specific implementation effect is worth further exploration.

\subsection{Data collection}

Considering the actual situation of the pilot work of "Waste Free City" in Xuchang City, 36 residents of Weidu and Jian 'an two central urban areas were selected as the main interviewees. The first-hand interview data were obtained through on-site in-depth interviews with interviewees. In addition, secondary data such as news reports and official government documents were collected and cross-verified with interview data to improve the reliability and validity of this study. The following is a summary of the interview.

Table 1: The Interview Outline

\begin{tabular}{|c|c|}
\hline Interview project & Specific problems \\
\hline Personal information & Gender, age, occupation, type of residential area \\
\hline \multirow{4}{*}{$\begin{array}{l}\text { The respondents' understanding } \\
\text { and participation in the "waste- } \\
\text { free city" and its driving factors }\end{array}$} & Do you know the construction status of Xuchang "Waste Free City"? \\
\cline { 2 - 2 } & What do you think is a "waste free city"? \\
\cline { 2 - 2 } & What ways do you participate in the construction of "Waste Free City" in your daily life? \\
\cline { 2 - 2 } & What factors will you consider when you participate in activities related to "Waste Free \\
& City"? \\
\cline { 2 - 2 } & What are your suggestions for the construction of "waste-free city"? \\
\hline
\end{tabular}

\section{The Research Process}

In this study, software NVivo12.0 was used for three-level coding, followed by saturation test and qualitative results analysis. In this study, 32 of the 36 interview data were randomly selected for coding, and another 4 were reserved for testing theoretical saturation. 


\subsection{Open coding}

Open coding is a process of word-for-word coding, labeling and conceptualization of the original data. In this study, through coding 32 randomly selected interview data, 15 categories were finally extracted.

\subsection{Axial Coding}

Axial Coding is to analyze and refine each category of open coding according to certain logic, and establish the logical relationship between concepts, so as to develop the category of spindle [16]. In this study, by combining and clustering 15 independent categories obtained from open coding, 6 main axis categories were obtained at the macro level.Axial coding and the corresponding category are shown in table 2 .

Table 2: Axial Coding and its Corresponding Categories

\begin{tabular}{|c|c|c|c|}
\hline $\begin{array}{l}\text { The main } \\
\text { categories }\end{array}$ & Category connotation & $\begin{array}{l}\text { Corresponding } \\
\text { categories }\end{array}$ & Initial concepts \\
\hline $\begin{array}{l}\text { Attitude to } \\
\text { Participation }\end{array}$ & $\begin{array}{l}\text { The public's cognition and judgment of } \\
\text { "waste free city", the public's } \\
\text { environmental responsibility and } \\
\text { environmental values }\end{array}$ & $\begin{array}{l}\text { "Waste - free city" } \\
\text { cognition, environmental } \\
\text { responsibility, } \\
\text { environmental values } \\
\end{array}$ & $\begin{array}{l}\text { Negative cognition, } \\
\text { environmental awareness, } \\
\text { environmental psychology }\end{array}$ \\
\hline The driving factor & $\begin{array}{l}\text { Publicity and education, reward and } \\
\text { punishment incentive and legal } \\
\text { restraint and other measures can guide } \\
\text { public behavior and form driving } \\
\text { factors }\end{array}$ & $\begin{array}{l}\text { Publicity and education, } \\
\text { reward and punishment } \\
\text { mechanism, laws and } \\
\text { regulations }\end{array}$ & $\begin{array}{l}\text { Laws and regulations, } \\
\text { environmental education, } \\
\text { Incentives and punishments } \\
\ldots \ldots\end{array}$ \\
\hline $\begin{array}{c}\text { Perceptual } \\
\text { behavioral control }\end{array}$ & $\begin{array}{l}\text { The perception of public participation } \\
\text { on the ability, energy, opportunity and } \\
\text { guarantee level of infrastructure } \\
\text { conditions of the construction of } \\
\text { "waste-free city" }\end{array}$ & $\begin{array}{l}\text { Participation opportunity } \\
\text { cognition, participation } \\
\text { behavior guarantee }\end{array}$ & $\begin{array}{l}\text { Knowledge and ability, } \\
\text { guarantee of participation in the } \\
\text { process } \\
\ldots \ldots\end{array}$ \\
\hline $\begin{array}{l}\text { The social } \\
\text { environment }\end{array}$ & $\begin{array}{l}\text { The government, enterprises, } \\
\text { communities, social organizations and } \\
\text { other subjects jointly influence the } \\
\text { social environment of the construction } \\
\text { of "waste-free city" }\end{array}$ & $\begin{array}{l}\text { Government action, group } \\
\text { influence, community } \\
\text { factor, enterprise factor }\end{array}$ & $\begin{array}{c}\text { The power of government, } \\
\text { management of business, } \\
\text { influence of voluntary groups } \\
\ldots \ldots\end{array}$ \\
\hline Subjective norms & $\begin{array}{l}\text { The moral norms followed by } \\
\text { individuals and the social group } \\
\text { pressure perceived when the public } \\
\text { participated in the construction of } \\
\text { "Waste Free City" }\end{array}$ & $\begin{array}{l}\text { Individual norms, social } \\
\text { pressures }\end{array}$ & $\begin{array}{l}\text { Value pursuit, } \\
\text { community impact } \\
\ldots \ldots\end{array}$ \\
\hline Identity and Traits & $\begin{array}{l}\text { The difference of public status, class } \\
\text { structure and individual personality } \\
\text { characteristics will lead to different } \\
\text { participation behaviors in the } \\
\text { construction of "waste-free city" }\end{array}$ & Identity and Traits & $\begin{array}{c}\text { Status, personality traits } \\
\ldots \ldots\end{array}$ \\
\hline
\end{tabular}

\subsection{Selective Coding}

Selective coding refers to the process of analyzing and refining the spindle coding again, and then digging out the "core category" which can play the role of summarizing, and then analyzing the relationship between the core category and non-core category and establishing the connection relationship. In this study, a model of influencing factors for public participation in the construction of "waste-free city" was constructed through selective coding, as shown in Figure 1. After that, the four interview data previously reserved were tested for saturation, and no new concepts and categories were shown. Therefore, it was determined that the model had achieved theoretical saturation 


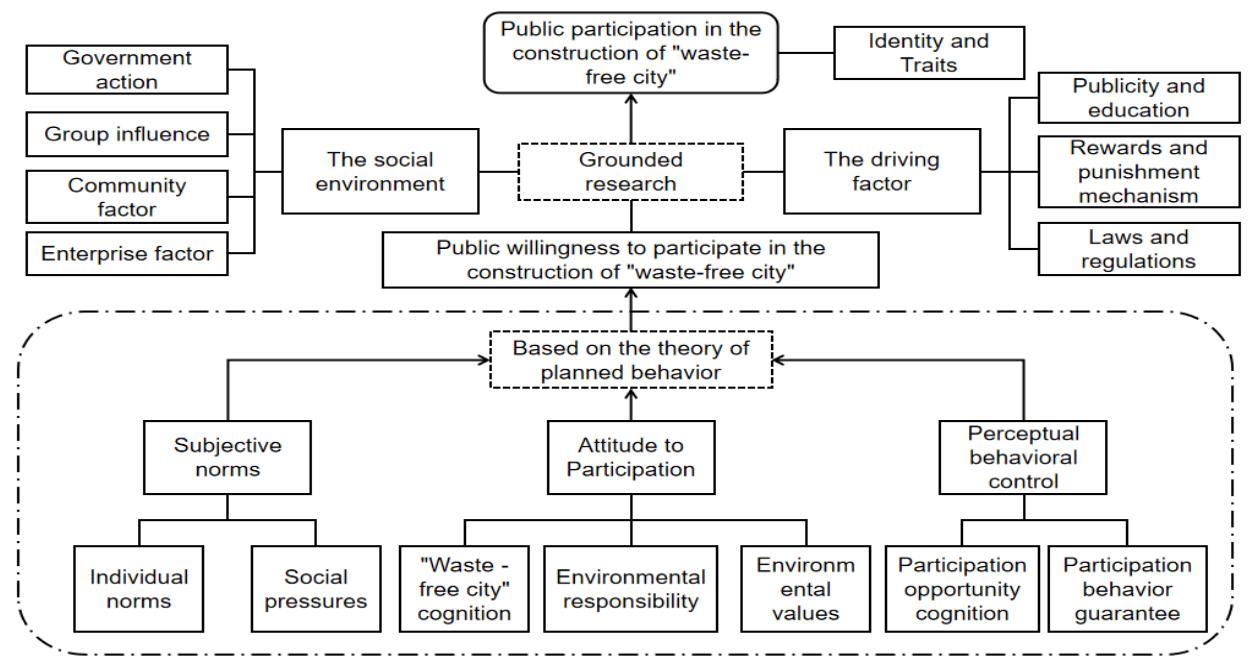

Fig. 1 : Influencing factor model of public participation in the construction of "waste-free city" from the perspective of grounded theory

\subsection{Model to interpret}

From the perspective of realizing the research purpose, the method of grounded theory is not only to construct the influencing factor model, but more importantly, to analyze the current situation and problems of public participation through the acquired theory. [17] Therefore, this study explains the internal mechanism of public participation in the construction of "waste-free city" from the following dimensions.

(1) Consistent with the theory of planned behavior, participation attitude, subjective norm and perceived behavioral control are the three main variables affecting behavioral intention. But its concrete connotation differs somewhat [18]. First, the attitude of participation refers to the attitude formed by the conceptualization of the positive or negative evaluation of a specific behavior. In the construction of "waste-free city", the participation attitude of the public is composed of the cognition of "waste-free city", the sense of environmental responsibility and the environmental values, which are the internal and prefactors influencing the participation of the public in the construction of "waste-free city". Secondly, subjective norms refer to the moral norms that individuals follow and the social group pressure they feel when taking a particular action, including individual norms and social pressure. Individual norms mainly include personal value pursuit, living habits and the influence from family and relatives. Social pressure refers to the collective norms from communities, units and groups. This kind of group pressure or collective norm will make the public form a motive to comply with the universal social pressure and promote the public to participate in the construction of "waste-free city". Third, the perceived behavioral control reflects the public's past experience and expected obstacles, and refers to the difficulty of the public's perceived participation in the construction of "Waste Free City", which is composed of the perception of participation opportunity and the guarantee of participation behavior. Participation opportunity cognition is an individual's speculation and judgment on whether he or she has the ability to complete a certain behavior. Participation guarantee refers to the guarantee factors of public participation in the construction process and effect of "waste-free city".

(2) Social environment. Social environment includes government behavior, group influence, community factor and enterprise factor, which belongs to external environment factor. According to sociological theory, social environment determines social consciousness and has an important influence on public behavior intention and behavior motivation. Under the large social background, the public is easily affected by the environmental policies of the government, as well as the incentives or constraints of corporate rules and systems, codes of conduct of communities and social groups, etc., thus forming their own behavioral value norms for treating the ecological environment and influencing their willingness and behavior to participate in the construction of "Waste Free City". 


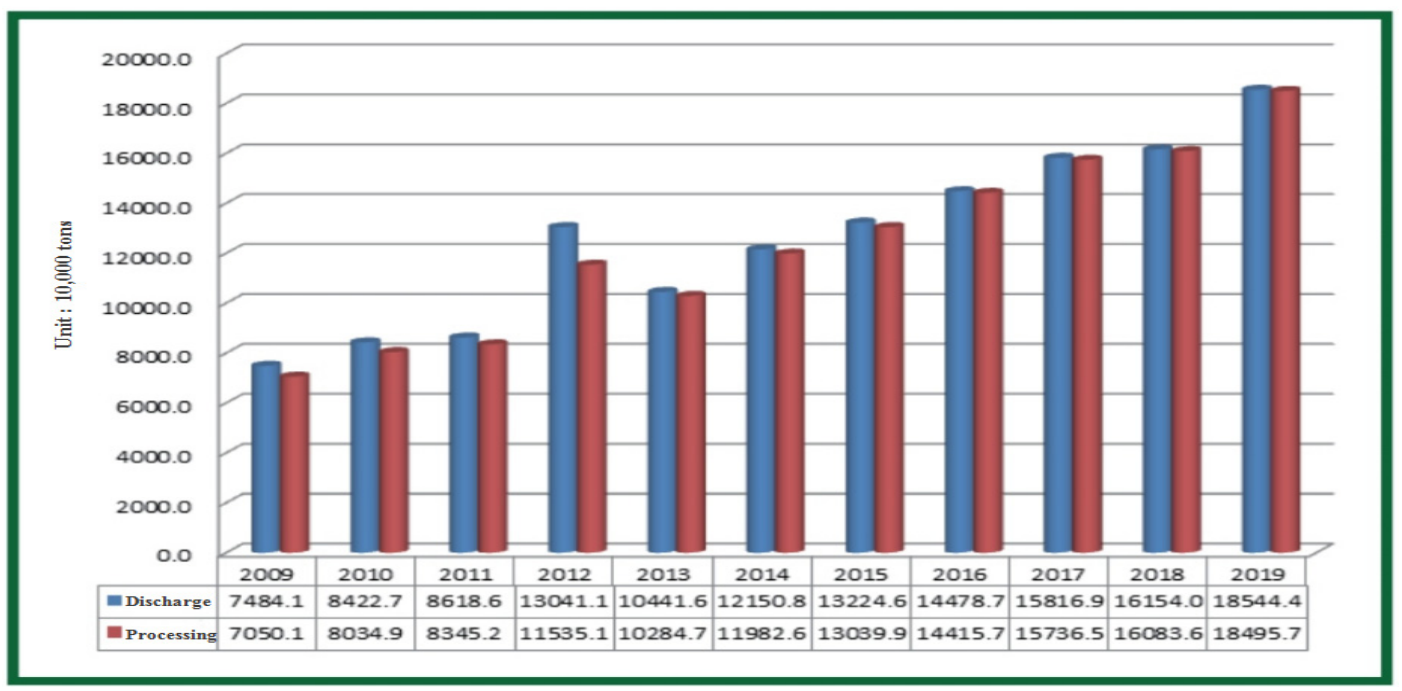

Fig. 2 : Production and disposal of MSW in key and model cities from 2009 to 2019 (Source: Ministry of Ecology and Environment, PRC)
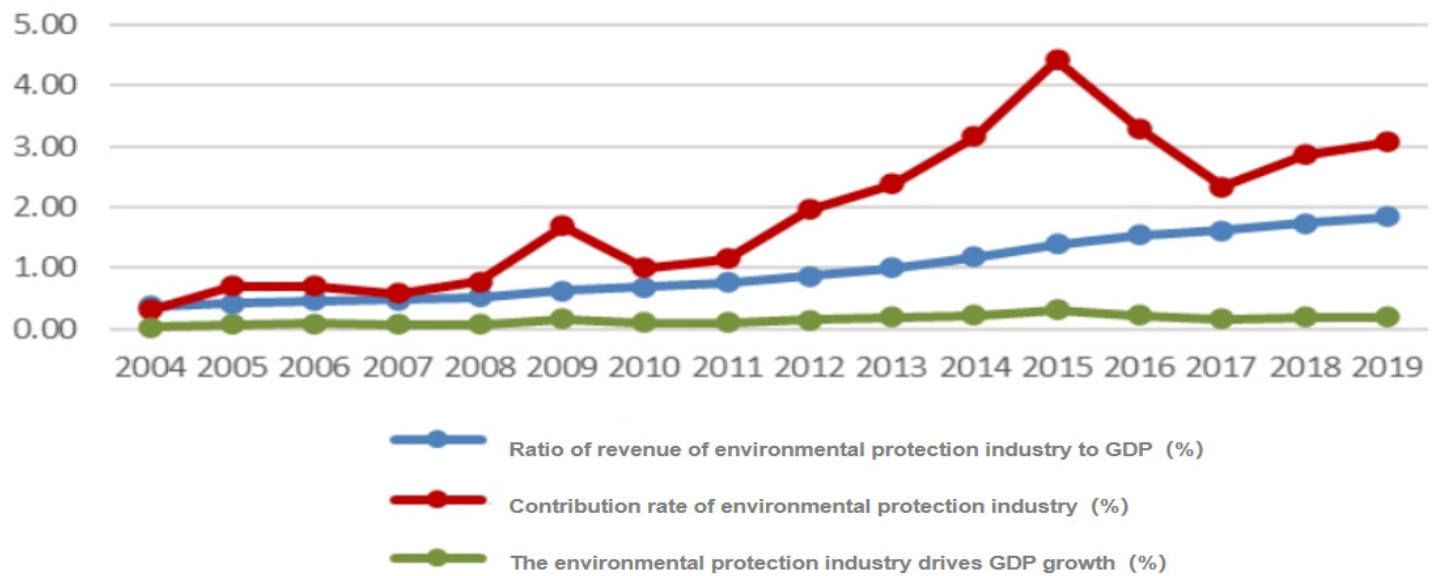

Fig. 3 : Contribution Rate of Environmental Protection Industry to National Economy (Source: China Environmental Protection Industry Association)

With the great attention and support from the government, the disposal capacity of MSW has been continuously improved, as shown in Figure 2. Figure 3 shows the contribution of the environmental protection industry to the national economy.

(3) Driving factors. Driving and promoting factors include publicity and education, reward and punishment mechanism, and laws and regulations. They are situational variables that affect public participation in the construction of "Waste Free City", and play a moderating role between psychological factors and external environmental factors. When the effect of this situational variable is weak, the public participation in the construction of "waste-free city" is mainly affected by internal psychological factors. When the effect of situational variables is significant, it may greatly promote or restrict the occurrence of public participation behavior. In the construction process of "waste-free city", the government mainly forms driving factors through strengthening publicity and education, establishing reward and punishment mechanism and improving laws and regulations, so as to improve public participation.

(4) Identity traits. Identity trait includes identity status and personality trait. Among them, status refers to the social role and class structure of the public. The public will make different considerations and judgments to participate in the construction of "waste-free city" based on the comprehensive consideration of social and economic status and social inequality. Personality traits reflect the individual's stable and unchangeable personality and psychological characteristics. According to the Big Five model of personality, there are about five traits that cover all aspects of personality description: openness, conscientiousness, extraversion, agreeableness, and neuroticism. Because the public have different personality traits, their participation in the construction of "waste free city" is also different.

\section{Conclusion and Discussion}

Taking the public participation in the construction of "waste-free city" in Xuchang as the sample, this study concluded through rooted analysis that six categories, including participation attitude, subjective norms, perceived behavior control, social environment, driving factors and identity traits, were the main factors affecting the public participation in the construction of "waste-free city". Specifically, the public's participation attitude, subjective norms and perceived behavior control directly affect the public's willingness to participate, which are 
internal psychological factors. The social environment constitutes the external environmental factors that affect public participation; The driving factors are situational variables, which play a moderating role between internal psychological factors and external environmental factors. The identity characteristics directly lead to the difference of public participation behavior.

The innovation and theoretical contribution of this study are as follows: First, it deeply excavates the connotation composition of the factors influencing public participation in the construction of "waste-free city", adds accumulation and material to enrich the system of public participation in ecological civilization construction, and makes up for the vacancy of the current research on public participation in the construction of "waste-free city". It has a certain reference significance for enhancing the enthusiasm of the public to participate in the construction of "waste-free city" and other ecological and environmental protection behaviors from a deep level. Second, it systematically sorted out the action mechanism of the factors influencing public participation in the construction of "waste-free city", combined subjective psychological activities with objective situational factors [19-23], which can more comprehensively analyze the influencing factors of public participation. Thirdly, it verifies and extends the theory of planned behavior, and well verifies the influence of behavioral attitude, subjective norms and perceived behavioral control on individual behavior. Based on the public participation in the construction of "Waste Free City" in Xuchang, the influencing factor model is built to expand the research direction and scope of the theory of planned behavior. Fourthly, taking the public participation in the construction of "waste-free city" in Xuchang as an example, primary materials are obtained based on field research and root analysis. The research conclusions are of reference significance for other pilot cities or regions to enhance the public participation effect.

Although this study is innovative in exploring the influencing factors of public participation in the construction of "waste-free city", it also has shortcomings and limitations, which need to be verified and improved through further empirical research. Specifically, it includes the following points: First, the data collection method of this study is mainly interview, and the open questionnaire and other forms are not used enough, and the diversity of methods needs to be improved. Second, the interview process is difficult to accurately and intuitively reflect the psychological activities of interviewees, and there may be some deviation in the way described by interviewees. Thirdly, different factors have different effects and intensities on public participation, so the government also needs differentiated implementation when taking specific measures to enhance public participation, which is not analyzed in depth in this study. Fourth, different identities and personality traits of the public will have a specific impact on their participation behaviors. Subfollow-up studies can be conducted to refine the study of citizens with different positions, fields and psychological characteristics, in order to more accurately enhance the effectiveness of public participation in the construction of "waste-free city".

\section{Acknowledgment}

This research is supported by the National Social Science Foundation of China (No.17CZZ022); Project of Social Science Achievements Evaluation Committee of Hunan Province (No.XSP17YBZZ111); Philosophy and Social Science Foundation of Hunan Province (No.16YBQ058)

\section{References}

1. Sohail, M. T., Mahfooz, Y., Azam, K., Yen, Y., Genfu, L., \& Fahad, S. Impacts of urbanization and land cover dynamics on underground water in Islamabad, Pakistan. Des, and water treat, 159, 402-411(2019).

2. Qiu Qiwen, Wen Xuefeng. Research Report on the Construction of "Waste Free Cities" in Japan [J]. Environmental Protection,48(Z1):57-60 (2020).

3. Wen Zongguo. Waste Free City: Theory, Planning and Practice. Beijing: Science Press,2020.

4. Sohail, M. T., Mahfooz, Y., Aftab, R., Yen, Y., Talib, M. A., \& Rasool, A. Water quality and health risk of public drinking water sources: a study of filtration plants installed in Rawalpindi and Islamabad, Pakistan. Des. and water treat., 181, 239-250 (2020).

5. Doe Xiaodong. Legal Regulation of Hazardous Waste Risks under the Construction of Waste Free Cities -Interpretation of "Three-dimensional Mechanism" and Exploration of "Three-dimensional Path". Journal of Social Sciences of Hunan Normal University, 49(03):1-10 (2020).

6. Sohail, M. T., Xiuyuan, Y., Usman, A., Majeed, M. T., \& Ullah, S. Renewable energy and non-renewable energy consumption: assessing the asymmetric role of monetary policy uncertainty in energy consumption. Environmental Science and Pollution Research, 1-10 (2021).

7. Zheng Junjun, Li Chengzhi, Liu Chunyan. Journal of Zhengzhou University (Philosophy and Social Sciences Edition),50(03):60-65+159 (2017).

8. Sohail, M. T., Aftab, R., Mahfooz, Y., Yasar, A., Yat, Y., Shaikh, S. A., \& Irshad, S. Estimation of water quality, management and risk assessment in Khyber Pakhtunkhwa and Gilgit-Baltistan, Pakistan. Desalination and Water Treatment, 171, 105-114 (2019).

9. Lu Yanzhao, Wu Xiaojing, Yan Wenjing. Study on the influencing factors of public participation in urban solid waste management. Journal of Arid Land Resources and Environment,31(11):21-25 (2017).

10. Sohail, M. T., Delin, H., Talib, M. A., Xiaoqing, X., \& Akhtar, M. M. An analysis of environmental law in Pakistan-policy and conditions of implementation. Research Journal of Applied Sciences, Engineering and Technology, 8(5), 644-653 (2014).

11. Yasara, A., Farooqa, T., Tabindaa, A. B., Sohailb, M. T., Mahfooza, Y., \& Malika, A. Macrophytes as potential indicator of heavy metals in river water. DESALINATION AND WATER TREATMENT, 142, 272-278 (2019). 
12. Sohail, M. T., Huang, D., Bailey, E., Akhtar, M. M., \& Talib, M. A. Regulatory framework of mineral resources sector in Pakistan and investment proposal to Chinese companies in Pakistan. American Journal of Industrial and Business Management, 3(05), 514 (2013).

13. Yang Jiaying, $\mathrm{Xu}$ Chun. Promoting public participation in ecological civilization construction through community intervention. Guangdong Social Sciences, (05):79-84 (2018).

14. Glaser B,Strauss AL.The Discover of Grounded Theory: Strategies for Qualitative Research. Nursing Research,17(4):377-380 (1968).

15. AJZENI. The Theory of Planned Behavior. Organizational Behavior and Human Decision Processes,50(2):179-211 (1991).

16. Mahfooza, Y., Yasara, A., Guijianb, L., Yousafb, B., Sohailc, M. T., Khanb, S., ... \& Khana, M. An assessment of wastewater pollution, treatment efficiency and management in a semi-arid urban area of Pakistan. DESALINATION AND WATER TREATMENT, 177, 167-175 (2020).

17. Yen, Y., Wang, Z., Shi, Y., Xu, F., Soeung, B., Sohail, M. T., ... \& Juma, S. A. The predictors of the behavioral intention to the use of urban green spaces: The perspectives of young residents in Phnom Penh, Cambodia. Habitat International, 64, 98-108 (2017).

18. Ma Bojun, Kang Hongyan. A Review of Behavioral Consumption Theory. Journal of Social Sciences of Hunan Normal University,42(03):101-107 (2013).

19. Xie Pengxin, Feng Jiaojiao, Yang Fu. Mediation Strategy of Local Government Collective Disputes and Its Influencing Factors -- A Rooted Study Based on Beijing Case. Chinese Administrative Management (03):115-122 (2021).

20. Sohail, M. T., Delin, H., \& Siddiq, A. Indus Basin Waters A Main Resource of Water in Pakistan: An Analytical Approach. Current World Environment, 9(3), 670 (2014).

21. Muhammad, A. M., Zhonghua, T., Dawood, A. S., \& Sohail, M. T. A Study to Investigate and Compare Groundwater Quality in Adjacent Areas of Landfill Sites in Lahore City. Nature Environment \& Pollution Technology, 13(1) (2014).

22. Chai, M., Deng, Y., \& Sohail, M. T. Study on Synergistic Mechanism of Water Environment Governance in Dongting Lake Basin Based on Evolutionary Game. In E3S Web of Conferences (Vol. 257, p. 03075). EDP Sciences (2021).

23. Zhao, P., Yen, Y., Bailey, E., \& Sohail, M. T. Analysis of urban drivable and walkable street networks of the ASEAN Smart Cities Network. ISPRS International Journal of Geo-Information, 8(10), 459 (2019). 